\title{
Lung-specific inactivation of CCAAT/ enhancer binding protein $\alpha$ causes a pathological pattern characteristic of COPD
}

\author{
L. Didon*,\# , A.B. Roos*, G.P. Elmberger", F.J. Gonzalez ${ }^{+}$and M. Nord*
}

ABSTRACT: The link between respiratory complications in prematurely born infants and susceptibility for developing chronic obstructive pulmonary disease (COPD) is receiving increasing attention. We have previously found that CCAAT/enhancer binding protein (C/EBP) activity in airway epithelial cells of COPD patients is decreased compared to healthy smokers, suggesting a previously unknown role for C/EBPs in COPD pathogenesis.

To investigate the role of the transcription factor $\mathrm{C} / \mathrm{EBP} \alpha$ in lung development and its potential role in COPD, mice with a lung epithelial-specific disruption of the C/EBPa gene (Cebpa ${ }^{\Delta L E}$ ) were generated using Cre-mediated excision, and the resulting pathology was studied during development and into adulthood.

$\mathrm{Cebpa}^{\mathrm{ALE}}$ mice exhibit impaired lung development and epithelial differentiation, as well as affected vascularity. Furthermore, $\mathrm{Cebpa}^{\mathrm{ALE}}$ mice that survive until adulthood develop a severe pathological picture with irregular emphysema; bronchiolitis, including goblet cell hyperplasia, bronchiolar metaplasia, fibrosis and mucus plugging; and an inflammatory cell and gene expression profile similar to COPD.

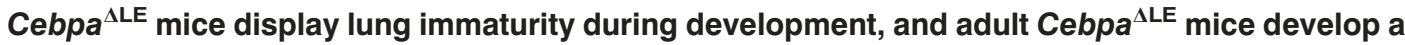
majority of the histopathological and inflammatory characteristics of COPD. Cebpa ${ }^{\Delta L E}$ mice could thus provide new valuable insights into understanding the long-term consequences of lung immaturity and the link to susceptibility of developing COPD.

KEYWORDS: Bronchiolitis, bronchopulmonary dysplasia, CCAAT/enhancer binding protein, chronic obstructive pulmonary disease, differentiation, emphysema

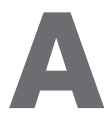
previously unknown role for a group of transcription factors called CCAAT/ enhancer binding proteins (C/EBPs) has been established in the regulation of lung gene expression over recent years [1]. C/EBP $\alpha$ is an important regulator of differentiation in lung and other organs such as liver and adipose tissue, where it stimulates the expression of genes characteristic of the mature differentiated organ and inhibits proliferation [2-4]. C/EBP $\beta$ and C/ $\mathrm{EBP}^{\delta}$ are also expressed in the lung [1-3] and despite a well-established role for C/EBPs in other tissues in the regulation of inflammation and immunological defences [1-3,5-7], as well as having a key role in differentiation, only a few studies have addressed the involvement of C/ EBPs in lung diseases $[8,9]$. We have previously found that the activity of $\mathrm{C} / \mathrm{EBP} \beta$ was markedly decreased in airway epithelial cells of chronic obstructive pulmonary disease (COPD) and chronic bronchitis patients [10], suggesting a potential role for $\mathrm{C} / \mathrm{EBPs}$ in the pathogenesis of COPD.

The increased number of survivors following extreme preterm birth with resulting pulmonary immaturity and often more acute complications, such as infant respiratory distress syndrome (IRDS) and long-term respiratory problems (chronic lung disease (CLD) of prematurity/bronchopulmonary dysplasia (BPD)), largely as a result of treatment, has resulted in an increased number of infants with respiratory problems surviving to adulthood ([11-13], and reviewed in BusH [14]). Lack of surfactant as a result of lung immaturity is a major cause of respiratory complications associated with

This article has supplementary material available from www.erj.ersjournals.com

For editorial comments see page 12 .

\section{AFFILIATIONS}

*Dept of Medicine, Division for Respiratory Medicine, Karolinska Institute, and

"Dept of Oncology and Pathology, Karolinska University Hospital,

Stockholm, Sweden.

\#Dept of Genetic Medicine, Weill Cornell Medical College, New York, $\mathrm{NY}$, and

+Laboratory of Metabolism, National Cancer Institute, National Institutes of Health, Bethesda, MD, USA.

CORRESPONDENCE

L. Didon

Dept of Genetic Medicine

Weill Cornell Medical College

1300 York Ave

W401

New York

NY 10065

USA

E-mail: lud2002@med.cornell.edu

Received:

Dec 062008

Accepted after revision:

June 302009

First published online:

July 162009 
preterm birth. Mice with a lung-specific inactivation of $\mathrm{C} / \mathrm{EBP} \alpha$ analysed just after birth display pulmonary immaturity, including disrupted surfactant production; this has been suggested by MARTIS et al. [15] as a model for the respiratory complications associated with lung immaturity and preterm birth. Other genes (e.g. ADAM33) that have a role in lung development have also been suggested to have a role in COPD, discussed in a review by BusH [14]. In that comprehensive review, it was suggested that the survivors of preterm birth, and especially those with CLD of prematurity (BPD), are an important cohort that may develop premature COPD later in life, a hypothesis further strengthened by more recent papers [12-14]. WONG et al. [13] reported a high prevalence of emphysema and pulmonary function abnormalities consistent with obstructive lung disease in young adult survivors of BPD, suggesting a susceptibility to development of COPD in survivors of BPD.

COPD is characterised by airflow limitation that is not fully reversible, and a chronic inflammatory response of the airways and lungs to noxious particles and gases, mostly cigarette smoke. The two main pathological lesions of COPD are destruction of lung parenchyma with enlargement of airspaces and loss of lung elasticity, i.e. emphysema, and inflammation of the small airways with airway wall thickening, infiltration of inflammatory cells, mucus plugging and peribronchiolar fibrosis [16-19]. Chronic bronchitis is a clinical diagnosis that is often, but not always, concurrent with COPD [16, 20]. COPD is a major public health problem and is the fourth leading cause of chronic morbidity and mortality in the USA today [19].

In the current study, we investigated the role of $\mathrm{C} / \mathrm{EBP} \alpha$ in the lung epithelium during late lung development and in the adult lung by generation of mice with a lung epithelial-specific disruption of the $\mathrm{C} / \mathrm{EBP} \alpha$ gene $\left(C e b p a^{\mathrm{LE}}\right)$. During late lung development, Cebpa ${ }^{\Delta \mathrm{LE}}$ mice displayed evidence of pulmonary immaturity with similarities to the histopathology in BPD infants [21], and adult Cebpa ${ }^{\Delta \mathrm{LE}}$ mice developed a severe pathological picture with the majority of the histopathological and inflammatory hallmarks of COPD. The survival rates of prematurely born infants with BPD are constantly improving and $C / E B P \alpha$ lung-deficient mice could provide valuable new insights into the long-term consequences of BPD and the recently described increased risk of developing COPD in young adult survivors of BPD [11-14].

\section{MATERIALS AND METHODS}

\section{Animals}

Mice with a lung-specific deletion of the C/EBP $\alpha$ gene (Cebpa) were achieved by Cre-mediated excision [22]. The Cre recombinase was specifically expressed in the lung epithelium under the control of the 3.7-kb human surfactant protein (SP)-C promoter in Sftpc-cre ${ }^{+}$hemizygous transgenic mice (kindly provided by $\mathrm{T}$. Okubo and B. Hogan (Dept of Cell Biology, Duke University Medical Center, Durham, NC, USA)) [23, 24]. The 3.7-kb human SP-C promoter is active in all lung epithelial cells and commences expression from at least embryonic (E)10 [24]. Sftpc-cre ${ }^{+}$mice on the ICR background were crossed with C/ $\mathrm{EBP} \alpha$ floxed mice $\left(\mathrm{Cebpa}^{\mathrm{fl} / \mathrm{fl}}\right.$ mice [25]) on a mixed 129 and C57BL/6 background, generating compound mutants (observed frequency of $62 \%$ ) hemizygous for the Cre transgene and heterozygous for the floxed Cebpa allele (Sftpc-cre $; \mathrm{Cebpa}^{\mathrm{fl} /+}$ mice). The Sftpc-cre ${ }^{+} ; \mathrm{Cebpa}^{\mathrm{fl} /+}$ compound mutants were crossed with homozygous $\mathrm{C} / \mathrm{EBP} \alpha$ floxed mice $\left(\mathrm{Cebpa}^{\mathrm{fl} / \mathrm{fl}}\right)$, generating compound mutants with a lung epithelial-specific disruption of the $\mathrm{C} / \mathrm{EBP} \alpha$ gene (Cebpa ${ }^{\Delta \mathrm{LE}}$ mice). Cebpa ${ }^{\Delta \mathrm{LE}}$ animals were killed at embryonic day 18.5 (E18.5), at postnatal day 9 (P9), and at 3 months of age (adult). For genotyping, DNA was extracted from tail biopsies using a QIAamp DNA mini kit (Qiagen, Hilden, Germany), and for PCR against $C e b p a^{\mathrm{fl} / \mathrm{fl}}$ we used the following primers: 5' - CCC GAC CCT CTA TAA AAG C - $3^{\prime}$ and 5' - TAG AGT TCT CCC GGC ATG G -3'. For PCR against $S f t p c-$ $\mathrm{Cre}^{+}$we used the following primers: $5^{\prime}-$ TCG ATG CAA CGA GTG ATG AG $-3^{\prime}$ and $5^{\prime}-$ TTC GGC TAT ACG TAA CAG GG $-3^{\prime}$. Sftpc-cre ${ }^{+}$mice were also crossed with the B6;129S4Gt(ROSA)26Sor ${ }^{\text {tm1Sor }} / \mathrm{J}$ strain (kindly provided by $\AA$. Bergström (Dept of Biosciences and Nutrition, Karolinska Institutet, Stockholm, Sweden)) and sacrificed at P15. The animal studies were approved by the Southern Stockholm Animal Welfare Ethics Committee and performed in compliance with international guidelines and Swedish law.

\section{Histology, immunohistochemistry and histological analysis} Embryos and lungs were isolated from the embryonic and postnatal stages described. Lungs were fixed at a constant pressure of $20 \mathrm{cmH}_{2} \mathrm{O}$. The number of animals per group analysed varied between three and five. Histology, immunohistochemistry and histological analysis were performed as previously described [2] with the following differences: some sections were briefly counter-stained using methylene green (Sigma, St Louis, MO, USA) solution (0.5\% methylene green in $0.1 \mathrm{M}$ sodium acetate buffer, $\mathrm{pH} 4.2)$. Tissues were stained with Miller's Elastin/van Gieson. Histological images were compared using the Pages and Preview software (Apple, Cupertino, CA, USA). All sections were classified according to standard histopathological criteria.

\section{Antibodies}

Primary antibodies used were: anti-C/EBP $\alpha(14 \mathrm{AAx})$ and antipro-SP-C (M-20) (both Santa Cruz Biotechnology, Santa Cruz, CA, USA); anti-thyroid transcription factor-1 (clone 8G7G3/1) (NeoMarkers, Fremont, CA, USA); anti- $\alpha$-smooth muscle actin ( $\alpha$-SMA; clone 1A4), anti-fibronectin (A0245) and anti-von Willebrand factor (vWF) (all DAKO, Glostrup, Denmark); antiepithelial-cadherin (E-cadherin) (BD Biosciences, San Jose, CA, USA); anti-phospho-histone H3 (Ser10) (Upstate, Charlottesville, VA, USA). The anti-Clara cell protein antibody (CC16) has been previously described [26] as well as the anti-cytokeratin (CK)-8 antibody [27] and the anti-forkhead box J1 (FoxJ1) antibody [28] (the latter a kind gift from S. Brody (Dept of Internal Medicine, Washington University School of Medicine, St Louis, MO, USA)). Biotinylated secondary antibodies were all from Vector Laboratories (Burlingame, CA, USA).

\section{LacZ staining}

Lungs from mice of P15 were fixed with $0.2 \%$ glutaraldehyde and $2 \%$ paraformaldehyde in PBS ( $\mathrm{pH} \mathrm{7.4)} \mathrm{for} 30 \mathrm{~min}$ at room temperature, rinsed for $90 \mathrm{~min}$ in $\mathrm{PBS}$ with $2 \mathrm{mM} \mathrm{MgCl}_{2}$ and $0.01 \% \mathrm{NP} 40$, and stained with X-Gal (2 mM $\mathrm{MgCl}_{2}, 0.01 \%$ NP40, $5 \mathrm{mM}$ potassium ferricyanide, $5 \mathrm{mM}$ potassium ferrocyanide and $1 \mathrm{mg} \cdot \mathrm{mL}^{-1} \mathrm{X}$-Gal in PBS) overnight on a shaker at $37^{\circ} \mathrm{C}$, embedded in paraffin, sectioned at $7 \mu \mathrm{m}$, and counterstained with Nuclear Fast Red (Vector Laboratories). 


\section{Mean linear intercept}

Mean linear intercept measurements were made using modified Image J software (a kind gift from J.S. Lee (Dept of Medicine, University of Pittsburg, Pittsburg, PA, USA); available at http://rsb.info.nih.gov/ij/). Ten 8-bit pictures from each animal were analysed. Large airways and blood vessels were manually removed from the image. A line grid composed of 1,353 lines was laid over the images, and the number of lines that ended on or intercepted alveolar tissue was then counted. The ratio of surface area to tissue volume and mean linear intercept was calculated using a method developed by Dunnill [29] and adapted by МсСомв [30].

\section{Quantitative RT-PCR}

Snap-frozen lung tissue was homogenised with a Polytron PT1200 (Kinematica, Lucerne, Switzerland). Total RNA was isolated using TRIzol reagent (Life Technologies, Inc., Grand Island, NY, USA) according to the manufacturer's instructions. RNA integrity was assessed in an Agilent 2100 Bioanalyzer (Agilent Technologies, Santa Clara, CA, USA). Total RNA $(2 \mu \mathrm{g})$ was reverse transcribed with a high-capacity RNA-tocDNA kit (Applied Biosystems, Foster City, CA, USA). The cDNA was amplified using Taqman master mix, probes and primers, and quantified according to the manufacturer's instructions with an ABI PRISM Sequence Detector 7700 (Applied Biosystems). All primers and probes were from Applied Biosystems. HPRT1 and 18S RNA were used as housekeeping genes for normalisation, and non-transcribed RNA was used as a negative control. All real-time PCR assays were performed in duplicate.

\section{Proliferation ratio}

A quantitative measurement of the ratio of phospho-histone H3-positive cells was performed by analysing a minimum of 500 cells in at least four areas per specimen using the Image J software.

\section{Statistical analysis}

All data are expressed as mean. Statistical analysis was performed using an unpaired t-test with Prism software (GraphPad Prism 5.02; GraphPad, San Diego, CA, USA). Differences were considered statistically significant when $\mathrm{p}<0.05$.

\section{RESULTS}

\section{Generation of mice with a lung epithelial-specific disruption of the gene for C/EBP $\alpha$}

Mice with a lung-specific disruption of the gene encoding C/ $\mathrm{EBP} \alpha\left(\mathrm{Cebpa}^{\mathrm{LEE}}\right.$ mice$)$ were produced by crossing of Sftpc-cre ${ }^{+}$ mice with $\mathrm{C} / \mathrm{EBP} \alpha$ floxed mice $\left(\mathrm{Cebpa}^{\mathrm{fl} / \mathrm{fl}}\right.$ mice [25]). Sftpc-cre ${ }^{+}$ mice were also crossed with Rosa26 reporter mice (ROSA26Sor ${ }^{\text {tm1Sor/tm1Sor }}$ ) that harbour the $\beta$-galactosidase gene (LacZ), to generate mice expressing LacZ in all cells where Cre is expressed, as well as in all cells originating from precursor cells where Cre has been expressed [31]. LacZ was expressed in all lung epithelial cells in about half of the Sftpc$\mathrm{Cre}^{+} ; R_{\text {RSA26Sor }}{ }^{\text {tm1Sor }}$ mice, whereas it was totally absent in the remainder of the Sftpc-Cre ${ }^{+}$ROSA26Sor ${ }^{\text {tm1Sor }}$ mice and in all ROSA26Sor ${ }^{\text {tm1Sor }}$ mice (fig. $1 \mathrm{a}$ and b). Both $\mathrm{Cebpa}^{\mathrm{fl} / \mathrm{fl}}$ and $\mathrm{Cebpa}^{\Delta \mathrm{LE}}$ mice were born in the expected Mendelian ratios. However, about $56 \%$ of the Cebpa ${ }^{\Delta \mathrm{LE}}$ mice died within hours of birth due to respiratory distress, in accordance with previous publications [15, 32-34]. When followed for up to 3 months, none of the Cebpa ${ }^{\Delta \mathrm{LE}}$ mice surviving the perinatal period died. The extent of $\mathrm{C} / \mathrm{EBP} \alpha$ gene disruption was assessed at $\mathrm{P} 9$ (alveolar stage) as well as at 3 months of age (adult stage). $\mathrm{Cebpa}^{\Delta \mathrm{LE}}$ mice that still expressed $\mathrm{C} / \mathrm{EBP} \alpha$ in the lung epithelium $(71 \%)$ were excluded from the study. Hereafter, "Cebpa ${ }^{\Delta \mathrm{LE}}$ mice" refers to mice that lack expression of $\mathrm{C} / \mathrm{EBP} \alpha$ in the lung epithelium. Consistent with previous findings [2], $\mathrm{C} / \mathrm{EBP} \alpha$ was expressed in alveolar type II cells as well as in cells in the conducting airway epithelium in lungs of Cebpa $a^{\mathrm{fl} / \mathrm{fl}}$ littermates (fig. 1c and d).

\section{Pulmonary immaturity in Cebpa ${ }^{A L E}$ mice}

At E18.5 (saccular stage) the future respiratory region of the lungs in $\mathrm{Cebpa}^{\mathrm{fl} / \mathrm{fl}}$ mice consisted of saccules lined by both squamous type I pneumocytes and cuboidal type II pneumocytes. At P9 (alveolar stage) the alveolar walls were being formed by septation in the Cebpa ${ }^{\mathrm{fl} / \mathrm{fl}}$ mice indicating structural maturation typical of these times of gestation (fig. 1e and g) [35]. On the contrary, Cebpa ${ }^{\Delta \mathrm{LE}}$ mice displayed an abnormal lung histopathology at E18.5 (saccular stage) and P9 (alveolar stage), characterised by prominent interstitial tissue in the alveolar septa and enlarged airspaces lined by undifferentiated cuboidal epithelial cells instead of differentiated type I and type II pneumocytes (fig. If and h).

\section{Adult Cebpa ${ }^{4 L E}$ mice develop bronchiolitis, emphysema, mucus plugging of the airways, macrophage accumulation and peribronchiolar lymphoid infiltrates}

In adult ( 3 months of age) and fully mature Cebpa ${ }^{\mathrm{fl} / \mathrm{fl}}$ mice, the alveolus is lined by squamous type I pneumocytes as well as secretory alveolar type II pneumocytes. The alveolar septae contains thin capillaries, elastic and collagen fibres as well as elastin-secreting myofibroblasts and a few fibroblasts (fig. 2a, c, e and g). In contrast, adult Cebpa ${ }^{\Delta \mathrm{LE}}$ mice surviving the perinatal lethality demonstrate a histopathological picture with the following. 1) Enlargement of airspaces and destruction of alveolar septa (as defined by free non-anchored arteriole), consistent with emphysema. The distribution of the emphysematous changes within the acinus was somewhat difficult to determine based on the irregular distribution. A definitive proximal acinar distribution could not be detected, so the classification as irregular emphysema is preferred (fig. 2b). 2) Abnormal cuboidal epithelial cells lining the alveolar ducts and alveoli adjacent to the bronchioles (bronchiolar metaplasia, fig. $2 d$ and f), mild centrilobular interstitial fibrosis (fig. 2f), dilated bronchioles containing necrotic material surrounded by a continuous layer or fragments of bronchiolar epithelium (bronchiolar ectasia, fig. 2d), goblet cell hyperplasia (compare fig. $2 i$ and $j$ ) as well as mucus plugging of the bronchioles (fig. 2d). These findings are pathologically defined as terminal bronchiolitis. 3) Extensive bronchiolar, alveolar and interstitial macrophage infiltration, existence of peribronchiolar lymphocyte infiltrates as well as airway neutrophilia and eosinophilia (fig. 2d, f and h).

The extent of alveolar enlargement and/or destruction over time in $\mathrm{Cebpa}^{\Delta \mathrm{LE}}$ mice was determined by morphometric analysis of the mean linear intercept in the peripheral lungs 


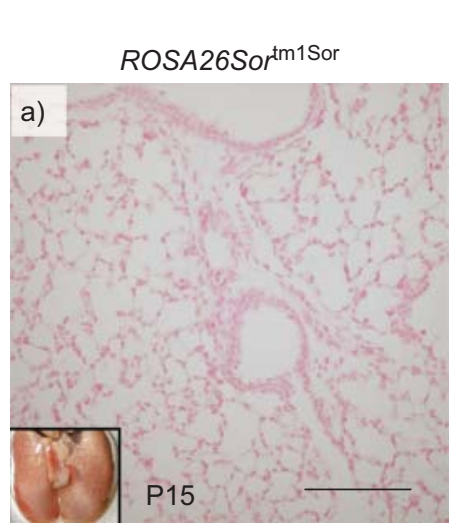

Cebpa fl/fl

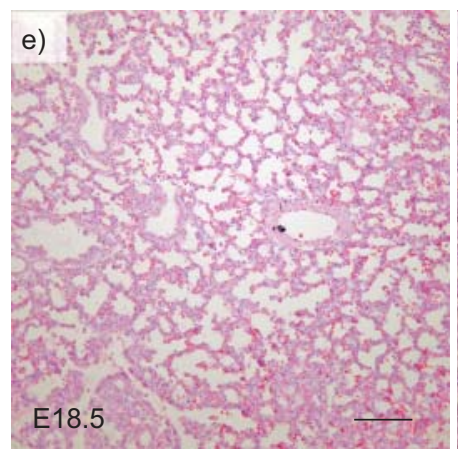

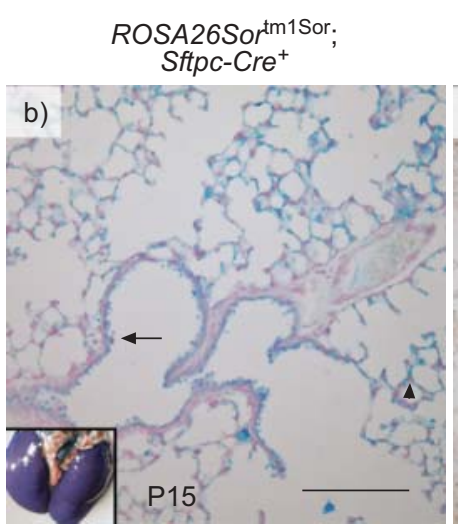

$\operatorname{Cebpa}^{\mathrm{LLE}}$

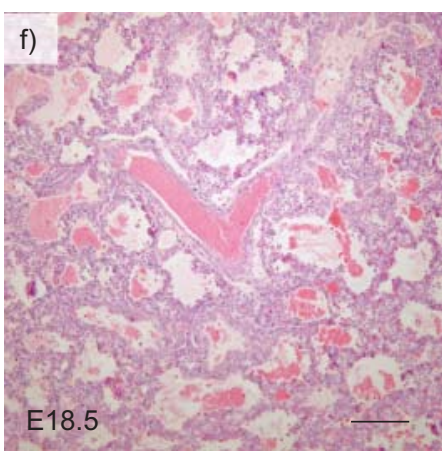

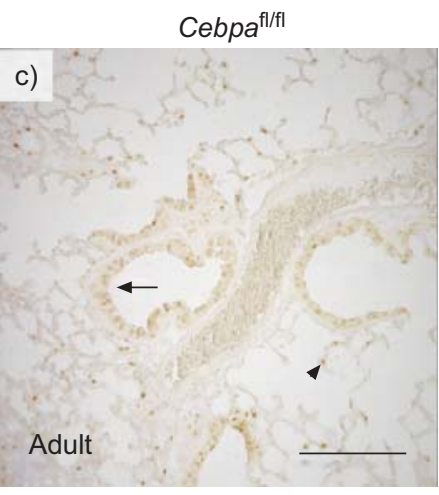

Cebpa $a^{\text {fl/fl }}$

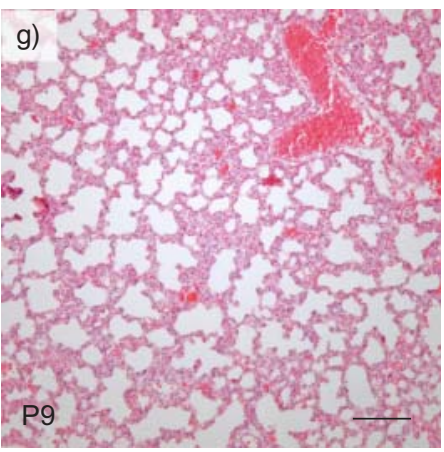

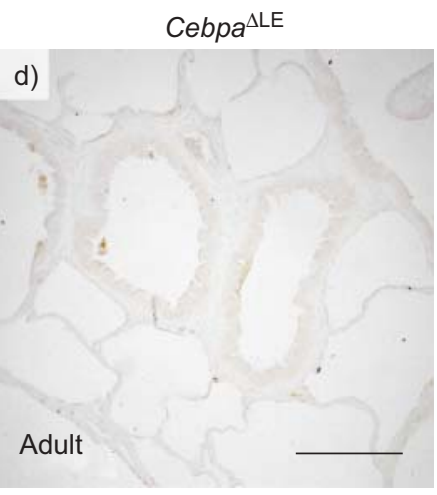

$\mathrm{Cebpa}^{\mathrm{LLE}}$

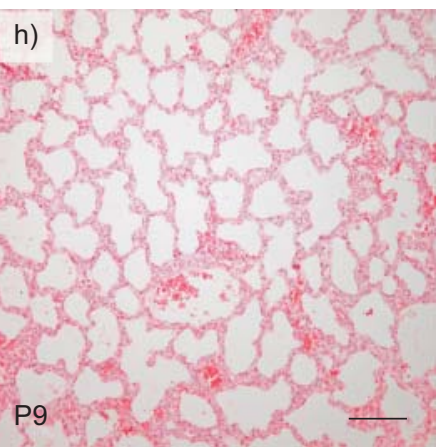

FIGURE 1. Mice with a lung epithelial-specific disruption of the gene for CCAAT/enhancer binding protein $\alpha(\mathrm{C} / \mathrm{EBP} \alpha)$ display pulmonary immaturity during late lung development. X-Gal staining of a) ROSA26Sor ${ }^{t m 1 S o r}$ mice and b) Sftpc-cre ${ }^{+}$;ROSA26Sor ${ }^{t m 1 S o r}$ mice at postnatal day (P) 15 sectioned and counter-stained with nuclear fast red The arrow indicates expression of LacZ (blue colour) in Sftpc-Cre ${ }^{+} ;$ROSA26Sor $^{\text {tm } 1 S o r}$ mice (b) in the conducting airway epithelium, and the arrowhead indicates expression in alveolar type II pneumocytes. Insets in lower left corners are pictures of whole mount X-Gal stainings prior to sectioning. Immunohistochemical staining (DAB, brown colour) for C/EBP $\alpha$ in Cebpa ${ }^{\mathrm{fl} / \mathrm{fl}}$ (c) and Cebpa ${ }^{\Delta \mathrm{LE}}$ mice (d) in adult lung; the arrow indicates expression of C/EBP $\alpha$ in Cebpa $\mathrm{f}^{\mathrm{fl} / \mathrm{fl}}$ mice in the conducting airway epithelium and the arrowhead indicates expression in alveolar type II pneumocytes. Haematoxylin-eosin staining of e and g) Cebpa $a^{\mathrm{fl} / \mathrm{fl}}$, and f and h) Cebpa ${ }^{\Delta L \mathrm{E}}$ mice in the saccular (embryonic day (E)18.5) (e and f) and alveolar period (P9) ( $g$ and h) of lung development. Scale bars $=200 \mu \mathrm{m}$.

(fig. 3a). A small, nonsignificant increase in alveolar size was seen in $\mathrm{Cebpa}^{\Delta \mathrm{LE}}$ mice compared to $\mathrm{Cebpa}^{\mathrm{fl} / \mathrm{fl}}$ mice at E18.5 (saccular stage). The increase of the mean linear intercept was more pronounced at P9 (alveolar stage), and reached statistical significance, and a substantially increased alveolar size was evident after 3 months (adult) in Cebpa ${ }^{\Delta \mathrm{LE}}$ mice.

\section{The inflammatory profile in $\mathrm{Cebpa}^{A L E}$ lungs resembles the profile in COPD}

The expression of inflammatory genes suggested to have a role in COPD [36] was analysed by quantitative RT-PCR in the lungs of adult Cebpa ${ }^{\Delta \mathrm{LE}}$ mice (fig. $3 \mathrm{~b}$ ). The expression profile with increased levels of tumour necrosis factor (TNF)- $\alpha$ and growthrelated oncogene (GRO)- $\alpha$ (a murine interleukin (IL)- 8 homologue) is similar to what has been previously described in stable COPD (reviewed in BARNES [36]). Together with the skewed T-cell immunoglobulin- and mucin-domain (TIM)-1/TIM-3 ratio (markers of T-helper cell (Th) type 1/Th2 differentiation), indicative of a Th1 dominance, this implies that not only are the numbers of macrophages and neutrophils elevated in the lungs of Cebpa $a^{\Delta \mathrm{LE}}$ mice, as in COPD, but also the molecular inflammatory profile is similar. Both the histopathological picture and the inflammatory cell and molecular profile of $\mathrm{Cebpa}^{\Delta \mathrm{LE}}$ mice display a clear similarity to human COPD.

\section{Disrupted differentiation of the conducting airways in Cebpa $^{\triangle L E}$ mice}

Antibodies against a panel of markers for airway epithelial cells, including CK-8, E-cadherin, CC16 and FoxJ1, were used to study the histology of adult lungs, and the development of the airways in Cebpa ${ }^{\Delta \mathrm{LE}}$ mice. CK-8 is selectively present apically in the future conducting airway epithelial cells in the lungs of both E18.5 (saccular stage) Cebpa ${ }^{\Delta \mathrm{LE}}$ and Cebpa ${ }^{\mathrm{fl} / \mathrm{fl}}$ mice (fig. $4 \mathrm{a}$ and b). Cebpa ${ }^{\mathrm{fl} / \mathrm{fl}}$ mice in the alveolar stage of lung development (P9), as well as adult (3 months) Cebpa ${ }^{\mathrm{fl} / \mathrm{fl}}$ mice, express CK-8 in the distal conducting airway epithelium as well as in the proximal conducting airway epithelium. However, at these stages of lung development, CK-8 is located along the entire cell membrane and, in addition, a weak expression is seen in individual alveolar epithelial cells (fig. 1c and e), strongly resembling the pro-SP-C expression pattern of alveolar type II pneumocytes (fig. $4 \mathrm{i}$ and k). P9 and adult $\mathrm{Cebpa}^{\Delta \mathrm{LE}}$ mice display the same CK-8 expression pattern in the conducting airway epithelium as Cebpa $a^{\mathrm{fl} / \mathrm{fl}}$ mice, but in contrast to $\mathrm{Cebpa}^{\mathrm{fl} / \mathrm{fl}}$ mice, Cebpa ${ }^{\Delta \mathrm{LE}}$ mice also strongly express CK-8 in groups of cells located in the alveolar walls and the interstitium (fig. $4 \mathrm{~d}$ and $\mathrm{f}$ ).

CC16 is a small secretory protein, suggested to have a role in regulating inflammatory processes in the lung $[37,38]$, and is 


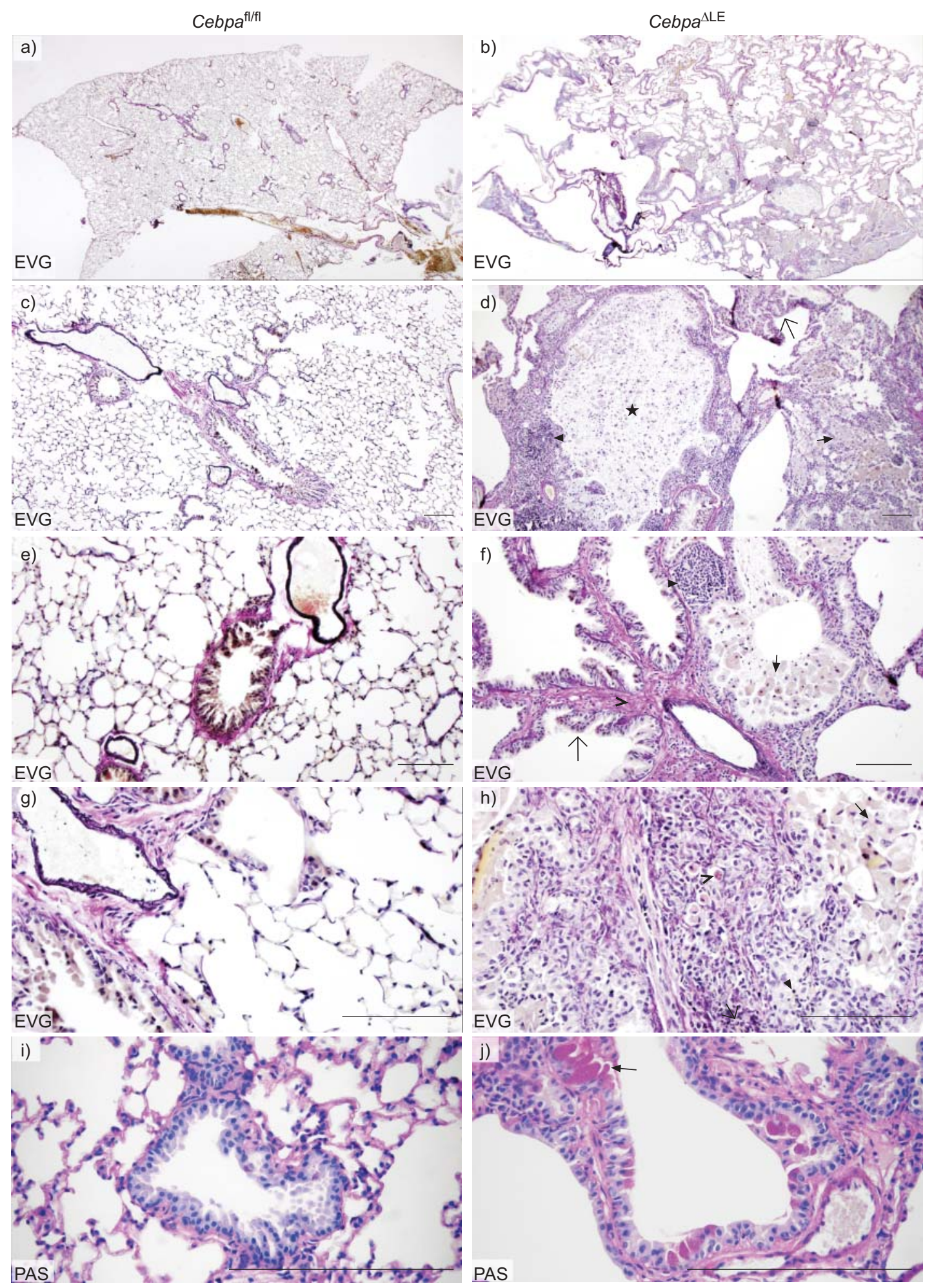

FIGURE 2. Elastin/van Giseon (EVG) staining of adult Cebpa ${ }^{\mathrm{f} / \mathrm{fl}}(\mathrm{a}, \mathrm{c}, \mathrm{e}$ and $\mathrm{g})$ and $\mathrm{Cebpa}^{\Delta \mathrm{LE}}(\mathrm{b}, \mathrm{d}, \mathrm{f}$ and $\mathrm{h})$ mice at increasing magnifications. Elastic fibres are coloured dark lilac, connective tissue red, muscle cells and erythrocytes yellow, and cell nuclei black-brown. b) Cross-section with irregular emphysema, bronchiolitis and mild diffuse and follicular bronchiolitis. d) Bronchiolitis with bronchioloectasia (star), mucoid impaction (star), accumulation of macrophages (arrow) and moderate chronic inflammation (arrowhead). A tendency to bronchiolar metaplasia is seen in surrounding alveoli (open arrow). f) Bronchiolitis with mild fibrosis (open arrowhead), slight chronic inflammation (arrowhead), accumulation of macrophages (arrow) and bronchiolar metaplasia (lambertosis) of surrounding centrilobular airspaces (open arrow). h) Inflammatory infiltrate of macrophages (arrow), lymphocytes (arrowhead), plasma cells often with Russel bodies (open arrowhead) and few neutrophilic granulocytes (open arrow). i-j) Periodic acidschiff (PAS) staining of adult Cebpa $a^{\mathrm{fl} / \mathrm{fl}}$ and Cebpa ${ }^{\Delta L \mathrm{E}}$ mice. Red/purple colour identifies mucin and carbohydrate macromolecules such as glycogen; arrows point out goblet cells. Scale bars $=200 \mu \mathrm{m}$. 

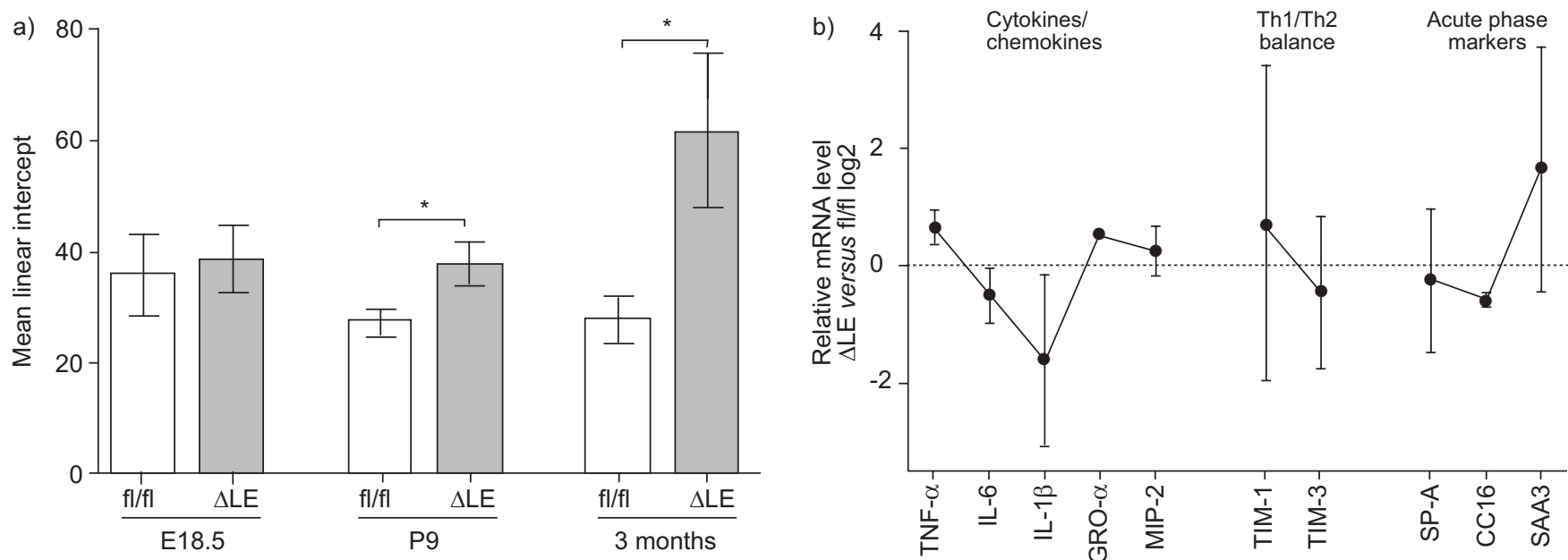

FIGURE 3. Mice with a lung epithelial-specific disruption of the gene encoding CCAAT/enhancer binding protein $\alpha$ (C/EBP $\alpha$ ) exhibit increased alveolar size and an inflammatory gene expression profile resembling the profile in chronic obstructive pulmonary disease (COPD). a) Morphometric analysis (mean linear intercept) of the peripheral lung at embryonic day (E) 18.5, postnatal day (P) 9 and in adult (3 months of age) mice. Error bars indicate SD. $\Delta \mathrm{LE}$ : Cebpa ${ }^{\mathrm{LLE}}$, i.e. mice lacking C/EBP $\alpha$ specifically in the lung epithelium; fl/fl: littermate controls. *: $\mathrm{p}<0.05$. b) Expression of inflammatory genes suggested to have a role in COPD [36] were analysed by quantitative RT-PCR Results are expressed as log2-fold induction (Cebpa ${ }^{\Delta \mathrm{LE}}$ versus littermate controls) with error bars indicating SEM. T-cell immunoglobulin- and mucin-domain (TIM)-1 and TIM-3 are markers of T-helper cell (Th) type 1 and Th2 differentiation respectively. TNF: tumour necrosis factor; IL: interleukin; GRO: growth-related oncogene; MIP: macrophage inflammatory protein; SP: surfactant protein; SAA3: serum amyloid A3.

expressed by Clara cells as well as similar serous secretory cells of the more proximal conducting airway epithelium [39]. As illustrated in figure 5a, CC16 is expressed by the majority of airway epithelial cells in adult $\mathrm{Cebpa}^{\mathrm{fl} / \mathrm{fl}}$ mice. In contrast, in Cebpa ${ }^{\Delta \mathrm{LE}}$ mice, CC16 displays an irregular expression pattern in the proximal conducting airway epithelium, with fewer CC16 expressing cells, many with an enlarged morphology and voluminous CC16 harbouring vesicles (fig. 5b). In the distal conducting airway epithelium, CC16 expression is readily detectable in Cebpa ${ }^{\Delta \mathrm{LE}}$ mice as well as Cebpa ${ }^{\mathrm{fl} / \mathrm{fl}}$ mice (data not shown).

E-cadherin is a $120-\mathrm{kDa}$ protein expressed in epithelial cells, where it is concentrated in cell-cell adherens junctions. In $C e b p a^{\mathrm{fl} / \mathrm{fl}}$ mice, E-cadherin is readily located along the lateral cell membrane, connecting neighbouring epithelial cells lining both the proximal and distal conducting airways (fig. 5c). In contrast, in Cebpa ${ }^{\Delta \mathrm{LE}}$ mice E-cadherin is expressed in cells lining the emphysematous airspaces with a cellular localisation typical of conducting airway epithelial cells, in addition to the expression in conducting airway epithelial cells. Furthermore, the epithelial marker E-cadherin is also expressed in cells interspersed within the lung interstitium of Cebpa ${ }^{\mathrm{LE}}$ mice, where it displays a diffuse intracellular distribution (fig. $5 \mathrm{~d}$ and data not shown). FoxJ1 is a transcription factor selectively expressed in ciliated airway epithelial cells [28]. Even though the airways of Cebpa ${ }^{\Delta \mathrm{LE}}$ mice are disrupted, FoxJ1 is expressed in the same proportion of cells in the conducting airways of $\mathrm{Cebpa}^{\mathrm{fl} / \mathrm{fl}}$ and Cebpa ${ }^{\Delta \mathrm{LE}}$ mice at E18.5, P9 and in adults (fig. 5e and $\mathrm{f}$, and data not shown; saccular, alveolar and adult stage, respectively). Together, the altered expression of these airway epithelial cell markers indicates disrupted differentiation of the conducting airways in mice lacking $\mathrm{C} / \mathrm{EBP} \alpha$ in the lung epithelium.

\section{Disrupted differentiation of alveolar type II cells in Cebpa $^{\triangle L E}$ mice}

We used immunohistochemistry against the alveolar epithelial type II cell marker pro-SP-C to study alveolar epithelial differentiation in the development of the pathological lung phenotype of Cebpa ${ }^{\mathrm{LEE}}$ mice. SP-C-expressing alveolar epithelial cells in the lungs of E18.5, P9 and adult Cebpa ${ }^{\Delta \mathrm{LE}}$ mice (saccular, alveolar and adult stage respectively) display an irregular dispersion within the hyperplastic alveolar walls mostly located in groups of two to three positive cells (fig. $4 \mathrm{~h}, \mathrm{j}$ and 1). In contrast, SP-C-expressing cells in Cebpa ${ }^{\mathrm{fl} / \mathrm{fl}}$ mice were mostly located individually, with the characteristic distribution of type II pneumocytes (fig. $4 \mathrm{~g}$, i and k). The distribution of SP-C-expressing cells is truly irregular in adult Cebpa ${ }^{\Delta \mathrm{LE}}$ mice ( 3 months) and the number of SP-C-expressing cells is increased compared to Cebpa ${ }^{\mathrm{fl} / \mathrm{fl}}$ mice. SP-C-expressing cells in $\mathrm{P} 9$ and adult Cebpa ${ }^{\mathrm{LLE}}$ mice (alveolar and adult stage) are located in the interstitial septa as well as cells lining the alveoli, as in adult Cebpa ${ }^{\mathrm{fl} / \mathrm{fl}}$ mice (fig. $4 \mathrm{j}$ and 1 ).

The transcription factor NK2 homeobox 1 (NKX2-1) expression, which together with $\mathrm{C} / \mathrm{EBP} \alpha$ is one of the key regulators of lung epithelial development, was restricted to the conducting airways and to alveolar type II cells in the peripheral lung saccules of $C e b p a^{\mathrm{fl} / \mathrm{fl}}$ mice at all ages (fig. A and C presented in the online supplementary material, and data not shown), as previously reported $[15,40]$. The expression pattern of NKX2-1 in Cebpa ${ }^{\Delta \mathrm{LE}}$ mice differs from that in $\mathrm{Cebpa} a^{\mathrm{fl} / \mathrm{fl}}$ mice. In E18.5 Cebpa ${ }^{\Delta \mathrm{LE}}$ mice (saccular stage), NKX2-1 is expressed in the proximal conducting airways and only in cells grouped in small tubes in the saccule walls, mostly resembling undeveloped distal airways (online supplementary fig. B). As in the E18.5 Cebpa ${ }^{\Delta \mathrm{LE}}$ mice (saccular stage), NKX2-1 is expressed in the airways and in what appears to be a mix of distal conducting airway epithelial cells 
CK-8
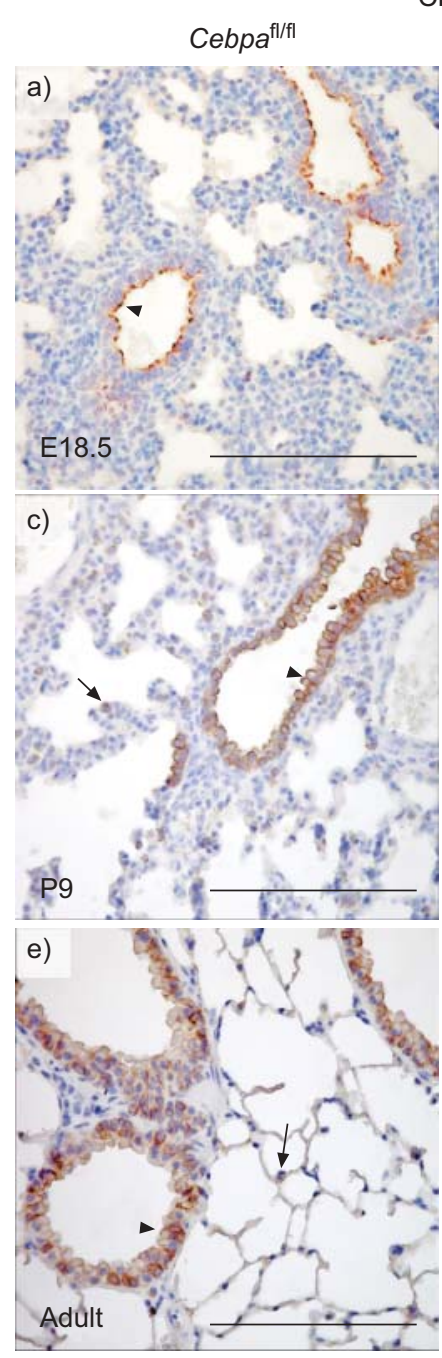
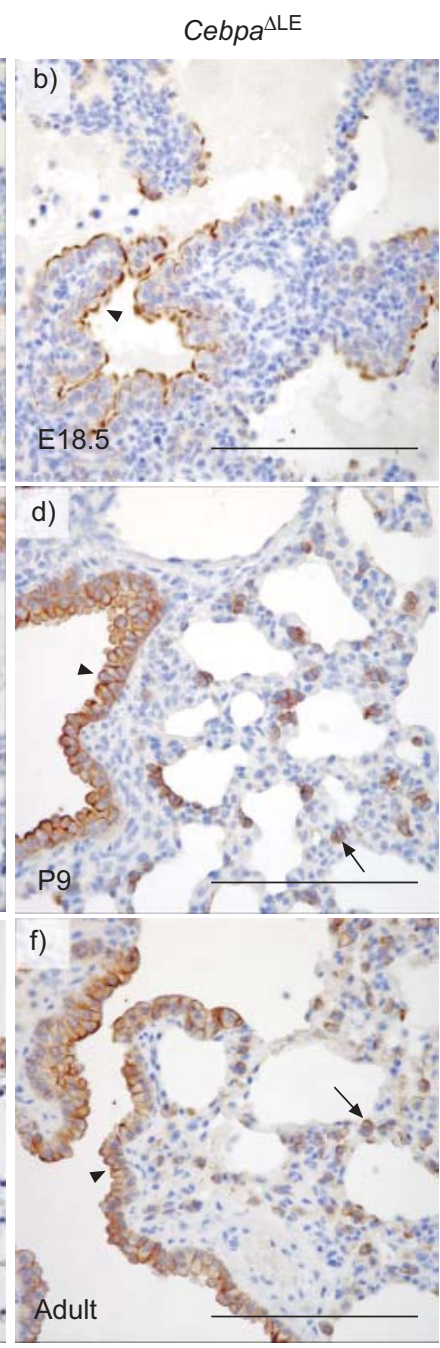

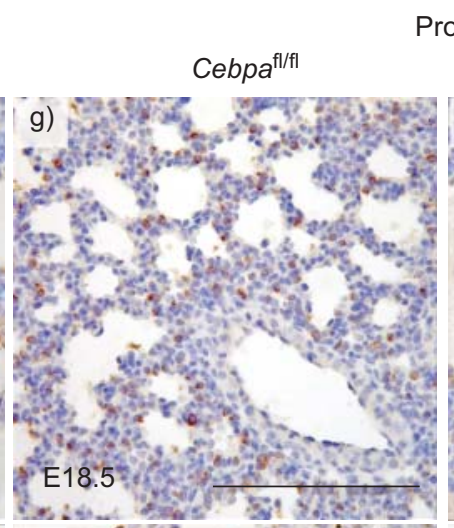

Pro-SP-C
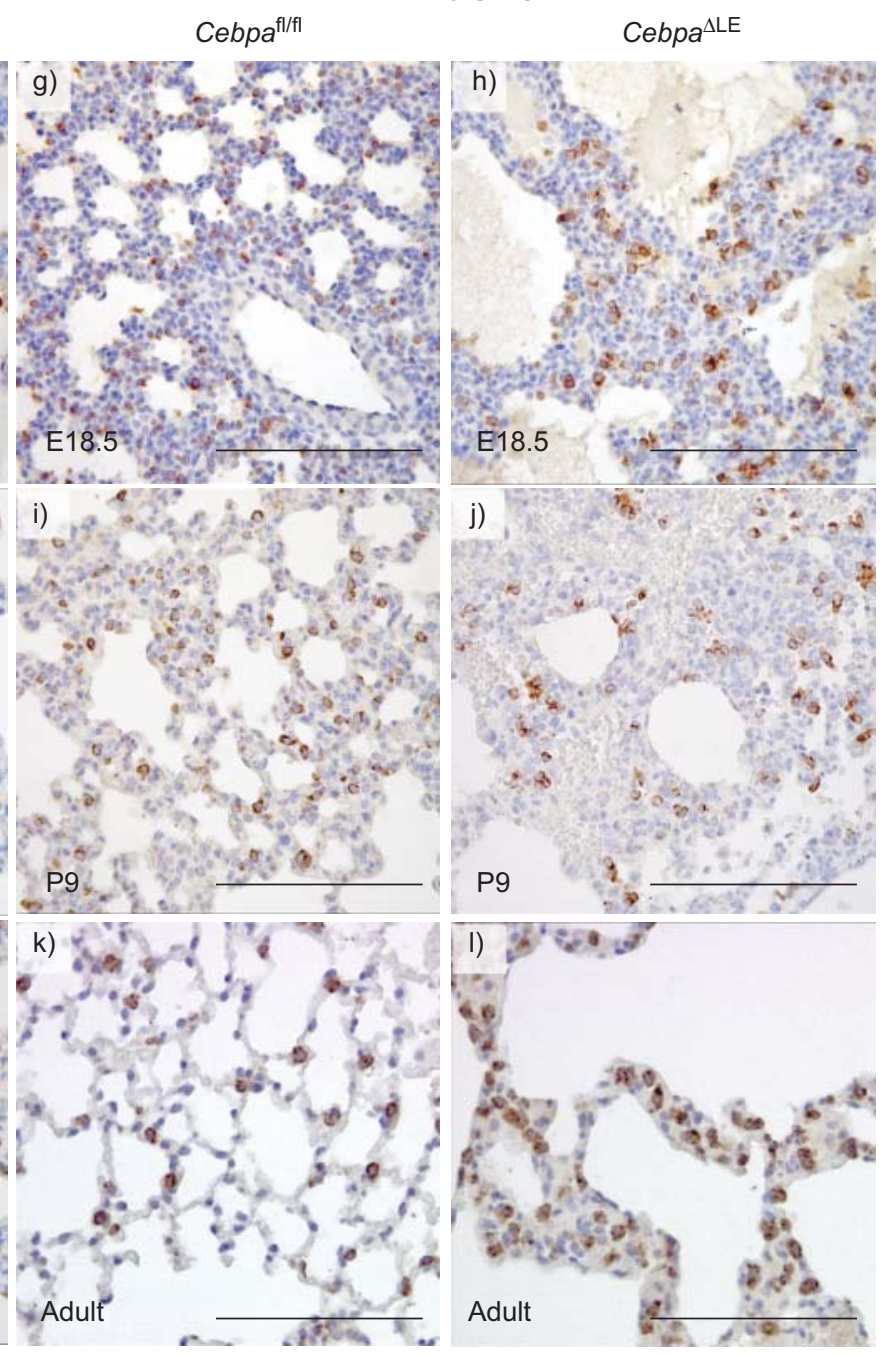

FIGURE 4. Mice with a lung epithelial-specific disruption of the gene for CCAAT/enhancer binding protein $\alpha(\mathrm{C} / \mathrm{EBP} \alpha)$ display impaired differentiation of the lung epithelium Immunohistochemical staining against the a-f) conducting airway epithelial cell marker cytokeratin (CK)-8 and the g-l) alveolar type II pneumocyte marker pro-surfactant protein (SP)-C in Cebpa ${ }^{\mathrm{fl} / \mathrm{fl}}$ and Cebpa ${ }^{\mathrm{LLE}}$ mice at embryonic day (E)18.5, postnatal day (P)9 (saccular and alveolar stage), and in adult (3 months of age) lungs. Arrows indicate positive cells in the alveolar region and arrowheads show positive cells in the conducting airway epithelium. Slides were slightly counter-stained with haematoxylin. Scale bars $=200 \mu \mathrm{m}$.

and undifferentiated alveolar type II cells in the alveolar wall of P9 (alveolar stage) and adult ( 3 months) Cebpa ${ }^{\Delta \mathrm{LE}}$ mice (online supplementary fig. D, and data not shown). Together, these results indicate disrupted differentiation of the alveolar epithelium as well in the Cebpa ${ }^{\mathrm{LE}}$ mice.

\section{Increased proliferation in Cebpa ${ }^{4 L E}$ mouse lung}

To investigate the relationship between cellular proliferation and $\mathrm{C} / \mathrm{EBP} \alpha$ expression during lung development, immunohistochemistry against phospho-histone H3 (P-H3), a marker for cell proliferation, was performed (fig. $6 \mathrm{a}-\mathrm{d}$ and data not shown). As expected, Cebpa ${ }^{\Delta \mathrm{LE}}$ mice have a higher ratio of proliferating cells than Cebpa ${ }^{\Delta \mathrm{LE}}$ mice (fig. 6e).

Cebpa $^{A L E}$ mice have disrupted dispersion of airway smooth muscle cells around the conducting airways and a thickened interstitium encapsulating the vasculature network

Disruption of the $\mathrm{C} / \mathrm{EBP} \alpha$ gene could also have secondary effects on the development of the smooth muscle cells surrounding the proximal conducting airways, as well as the myofibroblasts surrounding the distal conducting airways and the alveolar wall. Furthermore, the vascular network of the lung could potentially be affected, therefore immunohistochemistry against the smooth muscle cell and myofibroblast marker $\alpha$-SMA (fig. $6 f$ and g), along with the venous endothelial marker vWF (fig. 6h-m), was carried out in addition to the Elastin/van Gieson stainings (fig. 2a-h). In both E18.5 Cebpa $a^{\mathrm{fl} / \mathrm{fl}}$ and Cebpa ${ }^{\Delta \mathrm{LE}}$ mice (saccular stage), $\alpha$-SMA was expressed around the proximal conducting airways and blood vessels, as well as in the mesenchyme surrounding the distal conducting airways (data not shown). Postnatally, at P9 (alveolar stage) and in adult ( 3 months of age) Cebpa ${ }^{\Delta \mathrm{LE}}$ mice, smooth muscle cells around the conducting airways display a disrupted distribution, whereas the distribution of smooth muscle cells around the lung arteries exhibited no difference between $\mathrm{Cebpa}^{\mathrm{fl} / \mathrm{fl}}$ and Cebpa ${ }^{\Delta \mathrm{LE}}$ mice (fig. $6 \mathrm{f}$ and $\mathrm{g}$, and data not shown). The lung vasculature network in Cebpa ${ }^{\Delta \mathrm{LE}}$ mice was embedded in a thicker interstitium than in control 

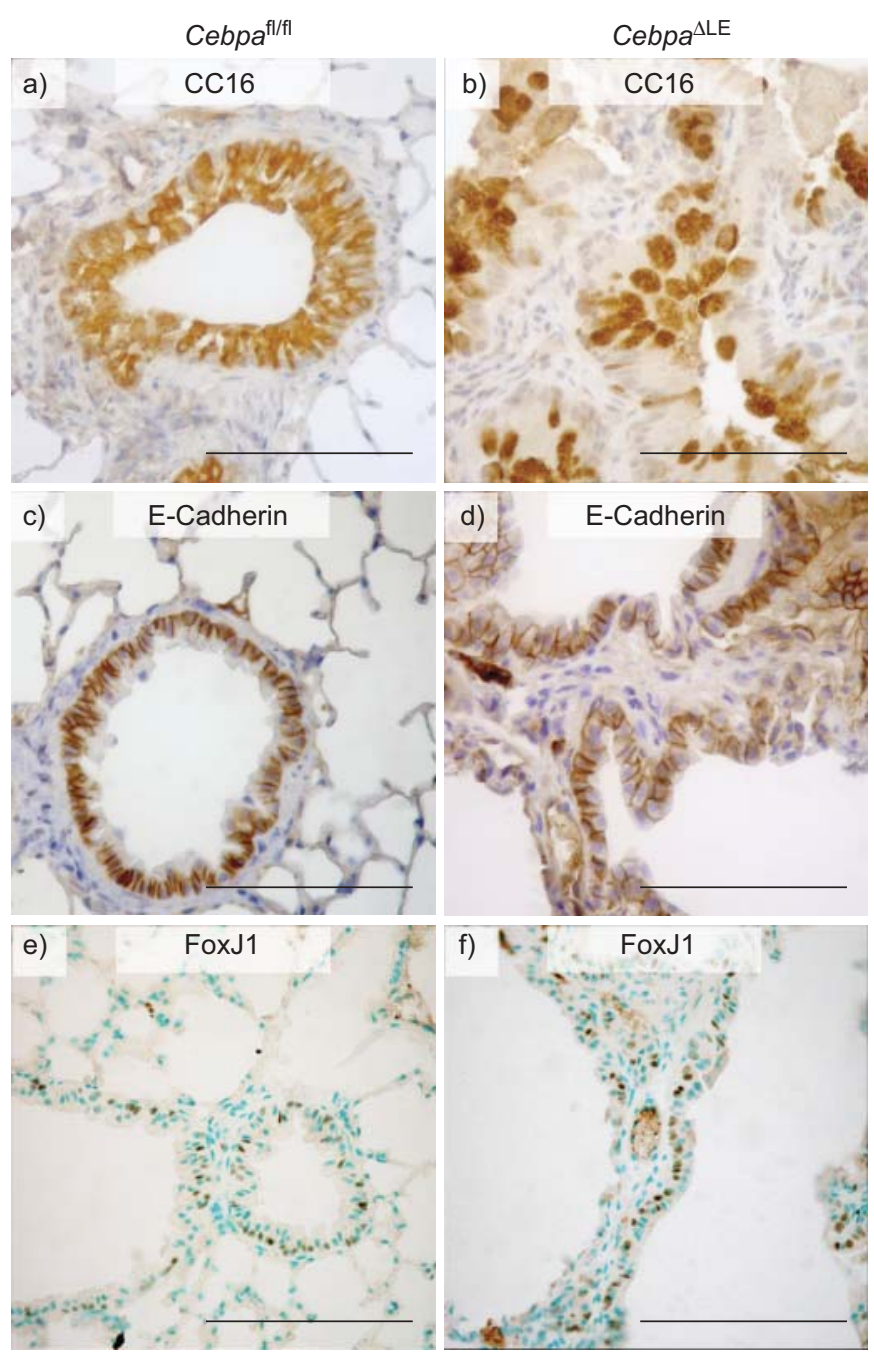

FIGURE 5. Loss of CCAAT/enhancer binding protein $\alpha(\mathrm{C} / \mathrm{EBP} \alpha)$ in the lung epithelium results in bronchiolar metaplasia. Immunohistochemical staining with $\mathrm{DAB}$ (brown) was performed on adult Cebpa ${ }^{\mathrm{fl} / \mathrm{fl}}$ and $\mathrm{Cebpa}^{\Delta \mathrm{LE}}$ mice for: $\mathrm{a}$ and $\mathrm{b}$ ) CC16, a C/EBP-regulated secretory protein of the conducting airways; $C$ and d) Ecadherin, a marker for the conducting airway epithelial cells; and e and f) FoxJ1, a marker for ciliated epithelial cells of the airways. Scale bars $=200 \mu \mathrm{m}$.

littermates with a more profound difference in adult mice (fig. 6h-m).

\section{DISCUSSION}

Mounting evidence suggests that CCAAT/enhancer binding proteins (C/EBPs) play a key role in the regulation of lung gene expression [1], and development of lung diseases such as COPD, asthma and lung cancer [8-10]. In the present study, we investigated the role of $\mathrm{C} / \mathrm{EBP} \alpha$ in the lung epithelium during late lung development, and in the adult lung, by generation of mice with a lung epithelial-specific disruption of the $\mathrm{C} / \mathrm{EBP} \alpha$ gene $\left(C e b p a^{\Delta \mathrm{LE}}\right)$. During late lung development, Cebpa ${ }^{\Delta \mathrm{LE}}$ mice displayed evidence of pulmonary immaturity with similarities to the histopathology in BPD infants [41], and adult Cebpa ${ }^{\Delta \mathrm{LE}}$ mice developed a severe pathological picture with the majority of the histopathological hallmarks of human COPD and a markedly similar inflammatory cell and gene expression profile.
We used the lung epithelial-specific Sftpc-cre ${ }^{+}$mice to inactivate the floxed $\mathrm{C} / \mathrm{EBP} \alpha$ gene $\left(\mathrm{Cebpa}^{\mathrm{fl}}\right)$ to produce $\mathrm{Cebpa}^{\Delta \mathrm{LE}}$ mice. To verify the activity and function of Crerecombinase from Sftpc-cre ${ }^{+}$animals, we also crossed these mice with ROSA26Sor ${ }^{\text {tm1Sor }}$ reporter mice. Not all Sftpc$\mathrm{Cre}^{+}$;ROSA26Sor ${ }^{\text {tm1Sor }}$ mice expressed LacZ, suggesting that the human Sftpc-promoter is inactive in some of the Sftpc-cre ${ }^{+}$ animals. A possible explanation for this could be a spontaneous inactivation of the human Sftpc-promoter, with a variable penetrance due to the mixed ICR/129/C57BL6 genetic background of the Sftpc-Cre ${ }^{+}$;ROSA26Sor ${ }^{\text {tm1Sor }}$ mice. A potential for cellular toxicity of transgenic Cre-expression in the lung epithelium has been previously discussed [42]; however, all the Sftpc-cre ${ }^{+}$;ROSA26Sor ${ }^{\text {tm1Sor }}$ mice that express LacZ have normal lung histology, suggesting that Sftpc-promoter driven Cre expression is not toxic in this genetic background, a background shared by the Cebpa ${ }^{\Delta \mathrm{LE}}$ mice.

During the saccular period (E17.5-E18.5) of murine lung development, the terminal lung buds dilate, the mesenchyme and epithelium thin out and there is extensive growth of pulmonary capillaries in close proximity to squamous respiratory epithelial cells (type I pneumocytes) as the gas exchange surface forms [35]. The final stage of lung maturation, known as the alveolar period (P5-P30 in mice), completes lung development with formation of alveoli by septation of the saccular airspaces. The histopathological picture of Cebpa ${ }^{\Delta \mathrm{LE}}$ mice during the saccular and alveolar period, with prominent interstitial tissue in the alveolar septa and enlarged airspaces lined by undifferentiated cuboidal epithelial cells instead of differentiated type I and type II pneumocytes, displays a resemblance to the respiratory complications associated with pulmonary immaturity [21]. However, pulmonary immaturity due to extreme preterm birth often results in chronic lung disease (CLD/BPD) mainly as a result of treatment, where lung inflammation is considered to be a central factor [43]. Cebpa $^{\mathrm{LE}}$ mice in the saccular and alveolar stages (E18.5 and P9) do not show any histopathological signs of inflammation and they are not subjected to any post-delivery treatments (e.g. mechanical ventilation, high oxygen treatment or surfactant supplements). Models of BPD have been created in premature baboons and lambs [44, 45], and by a variety of different approaches in rodents [46-48], and several also exhibit an inflammatory component. Similarly to Cebpa ${ }^{\Delta \mathrm{LE}}$ mice, mechanical ventilation of neonate mice with oxygen-rich gas increases the distal airspace size and induces remodelling without detectable lung inflammation [47], suggesting that the Cebpa ${ }^{\Delta \mathrm{LE}}$ mice still could have a role in understanding the spectrum of complications associated with lung immaturity.

The diagnosis of COPD is based on clinical, radiological and functional features but there are well-recognised histopathological correlates including: 1) inflammation of the small airways with airway wall thickening, infiltration of inflammatory cells, mucus plugging and peribronchiolar fibrosis; and 2) destruction of lung parenchyma with enlargement of airspaces and loss of lung elasticity, i.e. emphysema [16-19]. In $>90 \%$ of the cases of COPD in developed countries, the aetiological agent is longtime exposure to tobacco smoke and, more rarely, other environmental pollutants [18]. However, in light of recent publications by BUSH [14], WONG et al. [13] and others [11, 12], which suggest a strong relationship between respiratory 

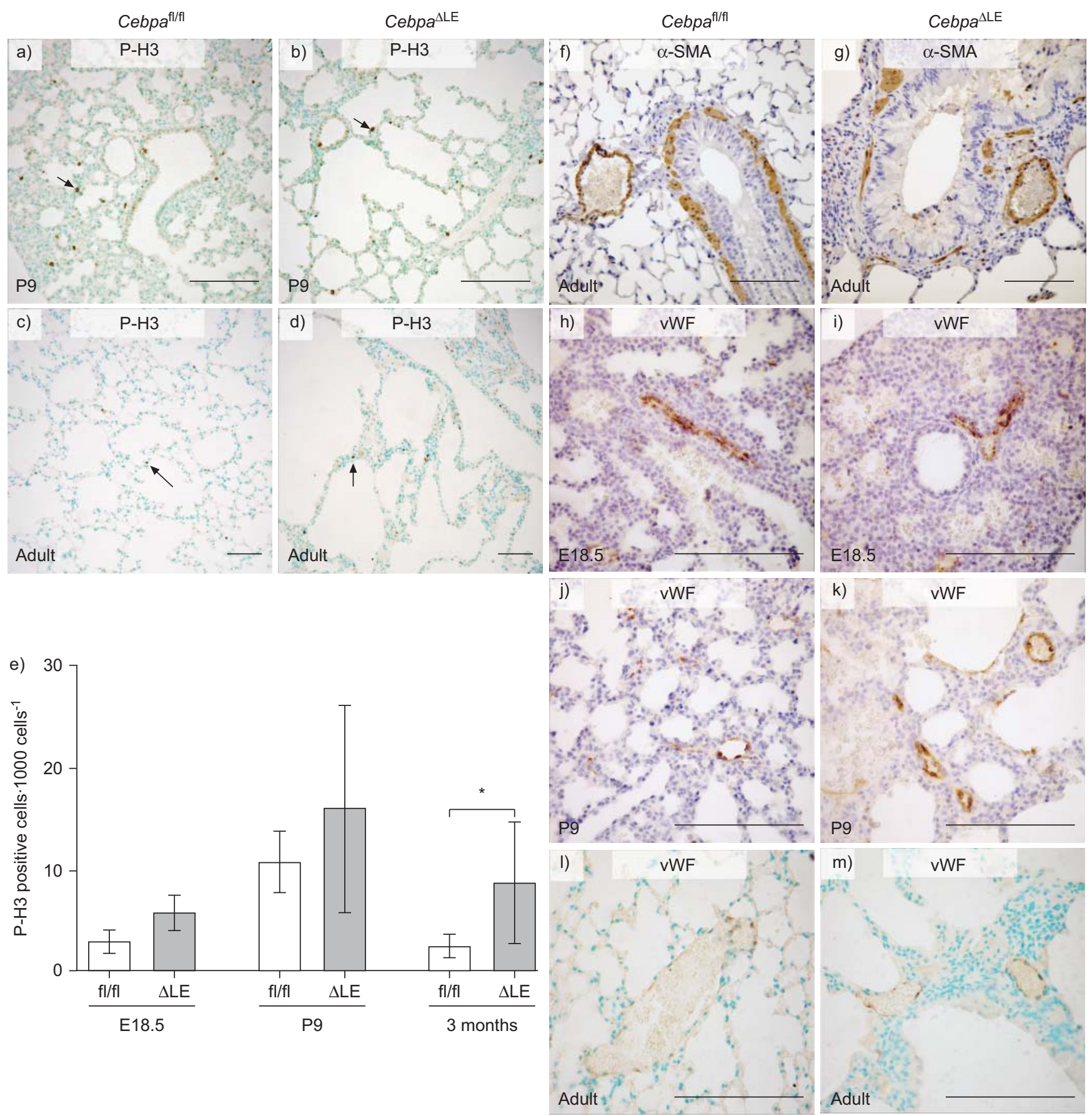

FIGURE 6. Loss of CCAAT/enhancer binding protein $\alpha(\mathrm{C} / \mathrm{EBP} \alpha)$ in the lung epithelium results in increased proliferation, disrupted distribution of airway smooth muscle cells around the conducting airways, as well as a thickened interstitium encapsulating the vasculature. a-d) Immunohistochemical stainings were performed against the mitosis marker phospho-histone $\mathrm{H} 3(\mathrm{P}-\mathrm{H} 3)$ on Cebpa ${ }^{\mathrm{fl} / \mathrm{fl}}$ and $\mathrm{Cebpa}^{\Delta \mathrm{LE}}$ mice in the saccular, alveolar and adult stages of lung development (embryonic day (E) 18.5 , postnatal day (P)9 and 3 months of age, respectively). Arrows indicate positive cells. e) The ratio of proliferating cells was determined by counting the number of P-H3 positive cells per 1,000 cells. Error bars indicate SD. $\Delta \mathrm{LE}$ : Cebpa ${ }^{\Delta \mathrm{LE}}$, i.e. mice lacking C/EBP $\alpha$ specifically in the lung epithelium; fl/fl: littermate controls. ${ }^{*}: p<0.05$. against $f$ and $g$ ) the smooth muscle cell marker $\alpha$-smooth muscle actin ( $\alpha$-SMA), and $h-m$ ) von Willebrand factor (vWF), a marker for venous endothelial cells. All slides were slightly counter-stained with methyl green $(a-d, I$ and $m)$ or haematoxylin $(f-k)$. Scale bars $=200 \mu m$.

complications in prematurely born infants and susceptibility for development of COPD as adults, factors other than tobacco smoke could also be of importance. Cebpa $a^{\Delta \mathrm{LE}}$ mice display signs of lung immaturity both during early $[15,34]$ and late (seen in the present study) lung development, and go on to develop an adult lung phenotype with a histopathology similar to that seen in COPD, including bronchiolitis, mucus plugging and emphysema. In addition, the inflammatory cell profile, similar to human COPD, is dominated by neutrophils and macrophages and exhibits Th1 dominance, and the inflammatory gene 
expression profile, with increased levels of TNF- $\alpha$ and the murine IL- 8 homologue GRO- $\alpha$, has a clear resemblance to COPD [36]. It is tempting to speculate that these two pathological processes share at least some underlying mechanisms, a possibility that now is also underpinned by recent clinical and epidemiological findings $[11,12,14]$.

Morphometric analysis of the lungs of Cebpa ${ }^{\Delta \mathrm{LE}}$ mice showed that there is a tendency to alveolar enlargement already in the saccular stage (E18.5), which becomes more pronounced in the alveolar stage (P9). The histology does not show any signs of tissue destruction at these stages of development, suggesting that the alveolar enlargement is initially caused by primary alveolar hypoplasia. However, the alveolar enlargement in $\mathrm{Cebpa}^{\Delta \mathrm{LE}}$ mice increases from $\sim 40 \%$ at E18.5, to $>200 \%$ in the adult emphysematic Cebpa ${ }^{\Delta \mathrm{LE}}$ lung. This increase, together with the observed inflammation with inflammatory cells such as neutrophils and macrophages (both suggested to have a key role in the destructive processes in COPD) and the histological signs of tissue destruction in the adult lungs, indicates that tissue destruction is also a likely contributing factor, in addition to a primary alveolar hypoplasia. Thus, the adult histopathological picture appears to be a result of both impaired development and later tissue destruction.

$\mathrm{C} / \mathrm{EBP} \alpha$ is known to be a regulator of cellular differentiation; this is why we made a detailed characterisation of how the lungs in $\mathrm{Cebpa}^{\Delta \mathrm{LE}}$ mice develop using a panel of cellular differential markers. The expression pattern of the airway and or alveolar epithelial cell markers CK-8, CC16, E-cadherin, SP-C, NKX2-1 and FoxJ1 clearly demonstrates that all levels of the lung respiratory tree, including the alveolus and alveolar parenchyma, are affected to different extents by the lung epithelial-specific disruption of $\mathrm{C} / \mathrm{EBP} \alpha$. CC16-expressing cells in the proximal conducting airways of adult Cebpa $a^{\Delta \mathrm{LE}}$ mice are reduced in number and display an enlarged morphology, with voluminous CC16 harbouring vesicles, suggesting that expression of the $\mathrm{C} / \mathrm{EBP} \alpha$-regulated $\mathrm{CC} 16$ gene is affected [26, 49], further supported by the decreased CC16 mRNA levels in quantitative PCR analyses. Still, both CC16 and CK-8 exhibit a normal cellular expression in the disrupted distal conducting airway epithelium of Cebpa ${ }^{\Delta \mathrm{LE}}$ mice. In adult mice, CK-8 is normally expressed in the conducting airway epithelium only; however, in the adult $C e b p a^{\Delta \mathrm{LE}}$ mice, CK-8 is also strongly expressed in groups of cells in the alveolar wall with resemblance to distal conducting airway epithelial cells, a process that pathologically could be described as bronchiolar metaplasia (lambertosis), as well as in cells within the interstitium. In Cebpa ${ }^{\Delta \mathrm{LE}}$ mice, E-cadherin, normally exhibiting an expression specific for the conducting airways, is aberrantly expressed both in cells within the interstitium as well as in cells lining the alveolar/emphysematic airspaces in proximity of bronchioles, further indicating bronchiolar metaplasia.

The distribution of cells expressing the alveolar epithelial type II cell marker pro-SP-C is truly irregular in postnatal Cebpa $a^{\Delta \mathrm{LE}}$ mice (alveolar and adult stage), with expression in cells located in the interstitial septa as well as cells lining the alveoli as in adult Cebpa $a^{\mathrm{fl} / \mathrm{fl}}$ mice. Furthermore, the number of SP-Cexpressing cells is increased compared to Cebpa ${ }^{\mathrm{fl} / \mathrm{fl}}$ mice, as previously described by BASSERES et al. [34] in embryonic
Cebpa ${ }^{\mathrm{LE}}$ mice. In addition, the lung epithelial transcription factor NKX2-1 shows an altered expression pattern in Cebpa ${ }^{\Delta \mathrm{LE}}$ mice with expression in the airways and in what appears to be a mix of distal conducting airway epithelial cells and undifferentiated alveolar type II cells in the alveolar wall. One possibility is that deletion of the $\mathrm{C} / \mathrm{EBP} \alpha$ gene that clearly inhibits lung epithelial cell differentiation gives rise to two different populations of cells with abnormal cellular morphology and localisation. One population of cells lining the emphysematous/alveolar airspaces expresses differentiation markers of both the conducting airway and the alveolar epithelium, something that pathologically would best be described as bronchiolar metaplasia or alveolar bronchiolisation, a lesion found in terminal bronchiolitis. The other population of cells expresses epithelial differential markers even though they are located in the thick alveolar interstitium of the Cebpa ${ }^{\Delta \mathrm{LE}}$ lung. Hence, this altered cellular location together with the interstitial fibrosis suggests a parallel process to the bronchiolar metaplasia, where epithelial cells could have transdifferentiated to mesenchymal cells (epithelial-mesenchymal transition) and induced increased extracellular matrix deposition.

$\mathrm{C} / \mathrm{EBP} \alpha$ is an inhibitor of proliferation and is absent from proliferating cells in other organs such as liver and fat [4]. In accordance with this, and previous results in embryonic $\mathrm{Cebpa}^{\Delta \mathrm{LE}}$ mice $[15,34]$, staining for P-H3, a marker for cell proliferation, revealed an increased cell proliferation in $\mathrm{Cebpa}^{\Delta \mathrm{LE}}$ mice compared to Cebpa $a^{\mathrm{fl} / \mathrm{fl}}$ mice. Thus, an increased proliferation of type II pneumocytes, as suggested by BASSERES et al. [34], could also be a contributing factor to the lung phenotype of $\mathrm{Cebpa}^{\mathrm{LE}}$ mice, in addition to the phenotype being a consequence of impaired differentiation and later destruction of the lung epithelium, as suggested by our results.

Disruption of the $\mathrm{C} / \mathrm{EBP} \alpha$ gene also appears to have secondary effects on the development of the surrounding mesenchyme. Postnatal (alveolar and adult stage) Cebpa ${ }^{\mathrm{LE}}$ mice have disrupted distribution of smooth muscle cells around the conducting airways. It remains to be determind whether this is a result of aberrant signalling between the epithelium and the mesenchyme, a process fundamental for lung development, or the result of adjusted dispersion of smooth muscle cells due to the altered architecture of the airways remains. Furthermore, $\mathrm{Cebpa}^{\Delta \mathrm{LE}}$ mice have a thicker interstitium that embeds the lung vasculature network in similarity to the histopathology of BPD lungs [21]. The underlying mechanism behind this is unclear, but could be a result of impaired differentiation of airway and alveolar epithelial cells resulting in an increased extracellular matrix deposition and interstitial fibrosis.

In conclusion, disruption of the $\mathrm{C} / \mathrm{EBP} \alpha$ gene in the mouse lung epithelium results in an impaired differentiation of alveolar pneumocytes and epithelial cells of the conducting airways generating undifferentiated cell populations at birth, and a postnatal histopathological pattern of lung immaturity that has resemblances to BPD. Furthermore, adult Cebpa ${ }^{\Delta \mathrm{LE}}$ mice surviving the embryonal lethality develop a severe pathological picture exhibiting the majority of the histopathological hallmarks of COPD, including bronchiolitis, emphysema, and extensive macrophage, neutrophil and lymphocyte infiltrations, and an inflammatory gene expression profile with 
clear similarities to human COPD. Our results further suggest that the adult phenotype is due both to a primary alveolar hypoplasia, and a later destructive process possibly secondary to the observed inflammation. The relative contributions of these to the phenotype, and if and how they are linked remain to be addressed.

The survival rates of prematurely born infants with immature lungs are constantly improving and an increasing number of survivors of extreme prematurity reach adulthood. The C/ $\mathrm{EBP} \alpha$-deficient mice could provide valuable novel insights into the link between long-term consequences from lung immaturity and respiratory complications in infants and the risk of developing COPD in young adulthood. Such knowledge will be of importance for shaping future clinical practices and treatments as survivors of BPD constitute a constantly increasing patient group, as a result of the remarkable advances during recent decades in treatment and survival or prematurely born infants.

\section{SUPPORT STATEMENT}

This work is supported by grants from the American Thoracic Society (grant no. ATS-06-035), the Swedish Research Council - medicine (grants 14677, 14678, 14794), the Swedish Heart-Lung Foundation (grant no. 20050443), the Jeansson, Åke Wiberg, Magnus Bergvall and Konsul Th C Bergh Research Foundations, the General Maternity Hospital Foundation and the Karolinska Institute (Stockholm, Sweden).

\section{STATEMENT OF INTEREST}

None declared.

\section{ACKNOWLEDGEMENTS}

The authors would like to thank: T. Okubo and B. Hogan (Dept of Cell Biology, Duke University Medical Center, Durham, NC, USA) for kindly providing the Sftpc-Cre $e^{+}$mice; S. Brody (Dept of Internal Medicine, Washington University School of Medicine, St Louis, MO, USA) for kindly sharing the FoxJ1 antibody together with helpful recommendations; J.S. Lee (Dept of Medicine, University of Pittsburg, Pittsburg, PA, USA) for kindly providing the modified Image J software; and $\AA$. Bergström (Dept of Biosciences and Nutrition, Karolinska Institutet, Stockholm, Sweden) for kindly providing the Gt(ROSA)26Sor ${ }^{\text {tm } 1 \text { Sor }} / \mathrm{J}$ mouse strain. The authors would also like to thank B. Hogan for critically reading the manuscript and giving helpful comments.

\section{REFERENCES}

1 Cassel TN, Nord M. C/EBP transcription factors in the lung epithelium. Am J Physiol Lung Cell Mol Physiol 2003; 285: L773L781.

2 Berg T, Didon L, Nord M. Ectopic expression of C/EBP $\alpha$ in the lung epithelium disrupts late lung development. Am J Physiol Lung Cell Mol Physiol 2006; 291: L683-L693.

3 Ramji DP, Foka P. CCAAT/enhancer-binding proteins: structure, function and regulation. Biochem J 2002; 365: 561-575.

4 McKnight SL. McBindall - a better name for CCAAT/enhancer binding proteins? Cell 2001; 107: 259-261.

5 Diamond G, Kaiser V, Rhodes J, et al. Transcriptional regulation of $\beta$-defensin gene expression in tracheal epithelial cells. Infect Immun 2000; 68: 113-119.

6 Musikacharoen $\mathrm{T}$, Matsuguchi $\mathrm{T}$, Kikuchi $\mathrm{T}$, et al. NF- $\mathrm{BB}$ and STAT5 play important roles in the regulation of mouse Toll-like receptor 2 gene expression. J Immunol 2001; 166: 4516-4524.
7 Poli V. The role of C/EBP isoforms in the control of inflammatory and native immunity functions. J Biol Chem 1998; 273: 29279-29282.

8 Halmos B, Huettner CS, Kocher O, et al. Down-regulation and antiproliferative role of C/EBPalpha in lung cancer. Cancer Res 2002; 62: 528-534.

9 Roth M, Johnson PR, Borger P, et al. Dysfunctional interaction of C/EBPalpha and the glucocorticoid receptor in asthmatic bronchial smooth-muscle cells. N Engl J Med 2004; 351: 560-574.

10 Didon L, Qvarfordt I, Andersson O, et al. Decreased CCAAT/ enhancer binding protein transcription factor activity in chronic bronchitis and COPD. Chest 2005; 127: 1341-1346.

11 Vrijlandt EJ, Gerritsen J, Boezen HM, et al. Lung function and exercise capacity in young adults born prematurely. Am J Respir Crit Care Med 2006; 173: 890.

12 Doyle LW, Faber B, Callanan C, et al. Bronchopulmonary dysplasia in very low birth weight subjects and lung function in late adolescence. Pediatrics 2006; 118: 108.

13 Wong PM, Lees AN, Louw J, et al. Emphysema in young adult survivors of moderate-to-severe bronchopulmonary dysplasia. Eur Respir J 2008; 32: 321-328.

14 Bush A. COPD: a pediatric disease. COPD 2008; 5: 53.

15 Martis PC, Whitsett JA, $\mathrm{Xu} \mathrm{Y}$, et al. C/EBP $\alpha$ is required for lung maturation at birth. Development 2006; 133: 1155-1164.

16 Travis W, Rosado-de-Christenson M, Colby $\mathrm{T}$, et al. Nonneoplastic Disorders of the Lower Respiratory Tract. Washington, American Registry of Pathology and the Armed Forces Institute of Pathology, 2002.

17 Barnes PJ. Chronic obstructive pulmonary disease. N Engl J Med 2000; 343: 269-280.

18 Barnes PJ. Small airways in COPD. N Engl J Med 2004; 350: 26352637.

19 Rabe KF, Hurd SS, Anzueto A, et al. Global strategy for the diagnosis, management, and prevention of chronic obstructive pulmonary disease: GOLD executive summary. Am J Respir Crit Care Med 2007; 176: 532-555.

20 Hargreave FE, Parameswaran K. Asthma, COPD and bronchitis are just components of airway disease. Eur Respir J 2006; 28: 264-267.

21 Bhatt AJ, Pryhuber GS, Huyck H, et al. Disrupted pulmonary vasculature and decreased vascular endothelial growth factor, Flt-1, and TIE-2 in human infants dying with bronchopulmonary dysplasia. Am J Respir Crit Care Med 2001; 164: 1971-1980.

22 Kwan KM. Conditional Alleles in Mice: Practical Considerations for Tissue-Specific Knockouts. New York, Genesis, 2002; pp. 49-62.

23 Okubo T, Knoepfler PS, Eisenman RN, et al. Nmyc plays an essential role during lung development as a dosage-sensitive regulator of progenitor cell proliferation and differentiation. Development 2005; 132: 1363-1374.

24 Okubo T, Hogan BL. Hyperactive Wnt signaling changes the developmental potential of embryonic lung endoderm. J Biol 2004 3: 11.

25 Lee $\mathrm{YH}$, Sauer B, Johnson PF, et al. Disruption of the C/EBP $\alpha$ gene in adult mouse liver. Mol Cell Biol 1997; 17: 6014-6022.

26 Nord M, Låg M, Cassel TN, et al. Regulation of CCSP (PCB-BP/ Uteroglobin) expression in primary cultures of lung cells involvement of C/EBP. DNA Cell Biol 1998; 17: 481-492.

27 Boller K, Kemler R, Baribault H, et al. Differential distribution of cytokeratins after microinjection of anti-cytokeratin monoclonal antibodies. Eur J Cell Biol 1987; 43: 459-468.

28 Blatt EN, Yan $\mathrm{XH}$, Wuerffel MK, et al. Forkhead transcription factor HFH-4 expression is temporally related to ciliogenesis. Am J Respir Cell Mol Biol 1999; 21: 168.

29 Dunnill MS. Quantitative methods in the study of pulmonary pathology. Thorax 1962; 17: 320-328.

30 McComb JG, Ranganathan M, Liu XH, et al. CX3CL1 up-regulation is associated with recruitment of CX3CR1+ mononuclear phagocytes and $\mathrm{T}$ lymphocytes in the lungs during cigarette smokeinduced emphysema. Am J Pathol 2008; 173: 949-961. 
31 Soriano P. Generalized lacZ expression with the ROSA26 Cre reporter strain. Nature genetics 1999; 21: 70-71.

32 Flodby P, Barlow C, Kylefjord $\mathrm{H}$, et al. Increased hepatic cell proliferation and lung abnormalities in mice deficient in CCAAT/ enhancer binding protein a. J Biol Chem 1996; 271: 24753-24760.

33 Wang ND, Finegold MJ, Bradley A, et al. Impaired energy homeostasis in C/EBP $\alpha$ knockout mice. Science 1995; 269: 11081112 .

34 Basseres DS, Levantini E, Ji H, et al. Respiratory failure due to differentiation arrest and expansion of alveolar cells following lung-specific loss of the transcription factor C/EBP $\alpha$ in mice. Mol Cell Biol 2006; 26: 1109-1123.

35 McDonald JA, ed. Lung Growth and Development. New York, Marcel Dekker, 1997.

36 Barnes P. The cytokine network in asthma and chronic obstructive pulmonary disease. J Clin Invest 2008; 118: 3546.

37 Stripp BR, Reynolds SD, Plopper CG, et al. Pulmonary phenotype of CCSP/UG deficient mice: a consequence of CCSP deficiency or altered Clara cell function? Ann N Y Acad Sci 2000; 923: 202-209.

38 Zhang Z, Kundu GC, Zheng F, et al. Insight into the physiological function(s) of uteroglobin by gene-knockout and antisensetransgenic approaches. Ann N Y Acad Sci 2000; 923: 210-233.

39 Nord M, Cassel TN, Braun H, et al. Regulation of the Clara cell secretory protein/uteroglobin promoter in lung. Ann N Y Acad Sci 2000; 923: 154-165.

40 Stahlman MT, Gray ME, Whitsett JA. Expression of thyroid transcription factor-1(TTF-1) in fetal and neonatal human lung. J Histochem Cytochem 1996; 44: 673-678.

41 Bhatt AJ, Pryhuber GS, Huyck H, et al. Disrupted pulmonary vasculature and decreased vascular endothelial growth factor,
Flt-1, and TIE-2 in human infants dying with bronchopulmonary dysplasia. Am J Respir Crit Care Med 2001; 164: 1971.

42 Whitsett JA, Perl AK. Conditional control of gene expression in the respiratory epithelium: A cautionary note. Am J Physiol Lung Cell Mol Physiol 2006; 34: 519-520.

43 Speer CP. Inflammation and bronchopulmonary dysplasia. Semin Neonatol 2003; 8: 29-38.

44 Bland RD, Ertsey R, Mokres LM, et al. Mechanical ventilation uncouples synthesis and assembly of elastin and increases apoptosis in lungs of newborn mice. Prelude to defective alveolar septation during lung development? Am J Physiol Lung Cell Mol Physiol 2008; 294: L3.

45 Maniscalco WM, Watkins RH, O'Reilly MA, et al. Increased epithelial cell proliferation in very premature baboons with chronic lung disease. Am J Physiol Lung Cell Mol Physiol 2002; 283: L991.

46 Bourbon J, Boucherat O, Chailley-Heu B, et al. Control mechanisms of lung alveolar development and their disorders in bronchopulmonary dysplasia. Pediatric Research 2005; 57: 38R.

47 Bland RD, Mokres LM, Ertsey R, et al. Mechanical ventilation with $40 \%$ oxygen reduces pulmonary expression of genes that regulate lung development and impairs alveolar septation in newborn mice. Am J Physiol Lung Cell Mol Physiol 2007; 293: L1099-L1110.

48 Warner B, Stuart LA, Papes RA, et al. Functional and pathological effects of prolonged hyperoxia in neonatal mice. Am J Physiol Lung Cell Mol Physiol 1998; 275: L110-L117.

49 Cassel TN, Nordlund-Moller L, Andersson O, et al. C/EBP alpha and $\mathrm{C} / \mathrm{EBP}$ delta activate the clara cell secretory protein gene through interaction with two adjacent C/EBP-binding sites. Am J Respir Cell Mol Biol 2000; 22: 469-480. 